\title{
A fortnightly atmospheric 'tide' at Bali caused by oceanic tidal mixing in Lombok Strait
}

\author{
Richard D. Ray ${ }^{1 *}$ (iD and R. Dwi Susanto 2,3
}

\begin{abstract}
Strong tidal currents in and around the narrow straits of the Lesser Sunda Islands, Indonesia, affect ocean sea surface temperatures (SST) via non-linear tide-induced mixing. A fortnightly spring-neap cycle in tidal currents can induce a similar cycle in SST, which has been observed to occur in and south of Lombok Strait. Here we report on an atmospheric response to the fortnightly SST cycle which is detected in relative humidity and air temperature measurements at Bali. The fortnightly cycles in both the ocean SST and the Bali atmospheric data have a strong seasonal cycle, with peak signals occurring during boreal summer.
\end{abstract}

Keywords: Tides, Spring-neap cycle, Tidal mixing

\section{Introduction}

Oceanic tidal mixing occurs in many shallow seas and near-coastal zones. In some places, the mixing can induce an oscillation in sea surface temperature (SST) at the near-fortnightly spring-neap period (e.g., Paden et al. 1991; Bisagni and Sano 1993; Souza and Pineda 2001). The mixing is accomplished by (usually) semidiurnal tidal currents which, on average, tend to lower near-surface temperatures during times of spring tides when the currents are strongest and mixing most intense.

Recently Iwasaki et al. (2015) reported that fortnightly oscillations in SST can induce a detectable local atmospheric response, an atmospheric "tide." In the Seto Inland Sea, the body of water separating the three Japanese islands of Honshū, Shikoku, and Kyūshū, these authors noticed a significant difference in SST between periods of spring tides versus neap tides, with the signal most evident during summertime when ocean stratification is most pronounced. This SST fortnightly oscillation was found to induce similar oscillations in the surrounding lower atmosphere, notably in surface air temperature and surface wind speed. Here we show that a (smaller) SST spring-neap tidal mixing signal in Lombok Strait of the

\footnotetext{
*Correspondence: richard.ray@nasa.gov

${ }^{1}$ Geodesy \& Geophysics Lab, NASA Goddard Space Flight Center, Greenbelt 20771, USA

Full list of author information is available at the end of the article
}

Lesser Sunda Islands of Indonesia also has a local atmospheric response which is detectable in meteorological data from the island of Bali.

The physical connection between Lombok oceanic SST and the Bali atmospheric measurements is conjectural but reasonable. The largest fortnightly SST signals in the southern Indonesia seas (see Fig. 1) occur in and around Lombok Strait and the shallower and narrower Alas Strait, and also around Sumba Strait farther to the east. The phases of the ocean and atmospheric signals, as shown below, are mutually consistent and also consistent with the phases of the spring-neap cycle in Lombok Strait, where spring tides lag the peak tidal potential by about two days. In addition, a strong seasonal modulation finds all signals most pronounced during the southeast monsoon season, a time when prevailing winds move from Lombok Strait onshore to Bali.

Reflecting the non-linear nature of ocean mixing, the actual frequency of interest here occurs at the difference of the frequencies of the two major semidiurnal tidal constituents, $S_{2}$ and $\mathrm{M}_{2}$, i.e., at the frequency $30.0000^{\circ} / \mathrm{h}-28.9841^{\circ} / \mathrm{h}$, or $1.0159^{\circ} / \mathrm{h}$ (period 14.765 days). This is also the frequency of the long-period tidal constituent MSf (Pugh and Woodworth 2014). In rare locations where a spring-neap cycle is caused by the major diurnal constituents $\mathrm{O}_{1}$ and $\mathrm{K}_{1}$, the frequency shifts to $1.098^{\circ} / \mathrm{h}$ (period 13.66 days), which is also the frequency of the long-period constituent Mf. We will 


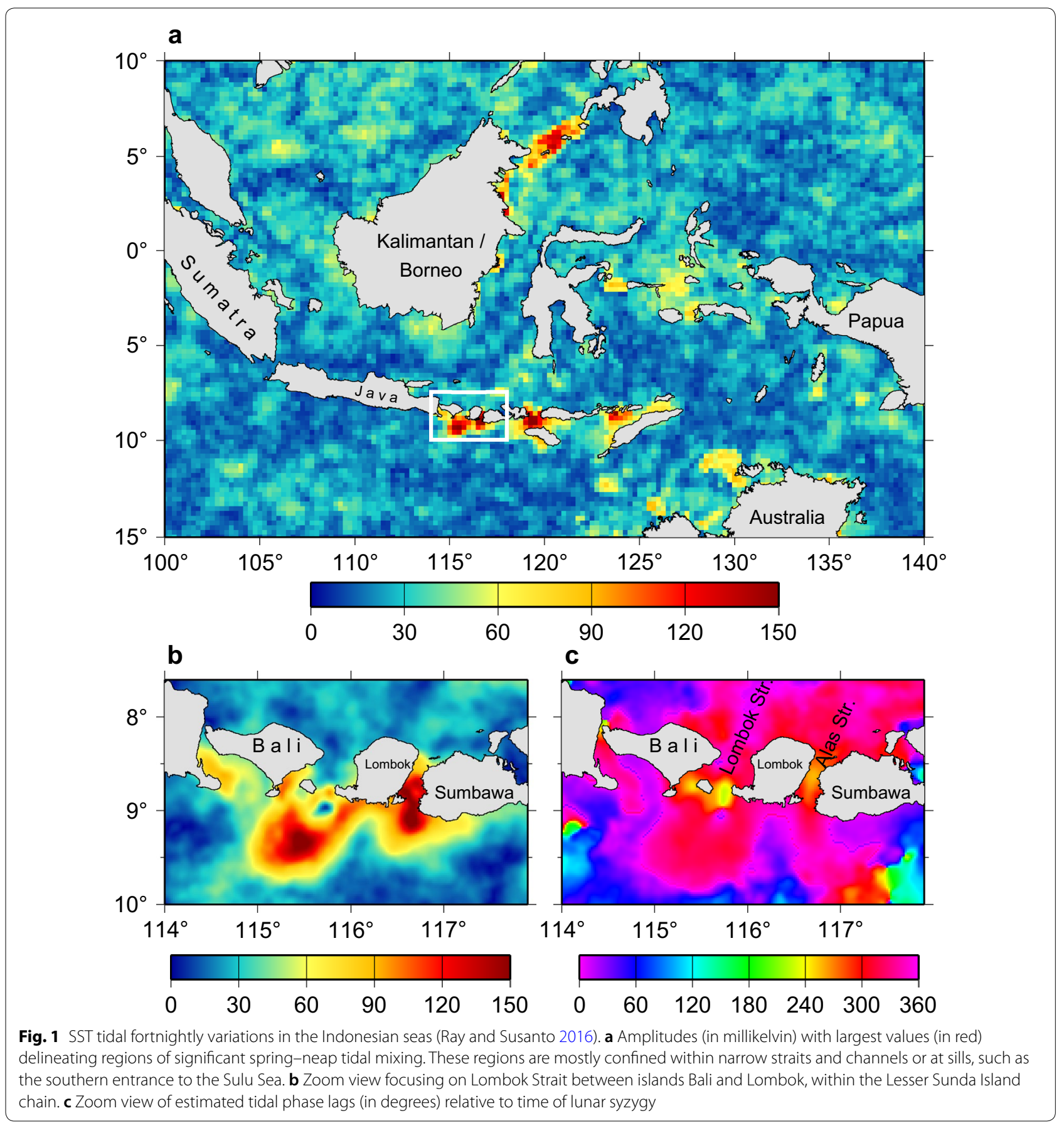

use MSf as a convenient label for the spring-neap signal, but it is important to realize that MSf tidal currents themselves have nothing to do with the SST signal at this period. MSf tidal currents are far too weak to affect ocean stratification [(see also the discussion by Griffin and LeBlond (1990)]. It is the change in semidiurnal currents over a fortnight that is affecting SST.
Following Iwasaki et al. (2015), we may call the atmosphere's response to the SST an atmospheric tide, although it obviously does not conform to conventional planetary-scale tides that are forced by the gravitational or radiational potentials. It is more akin to non-migrating components of solar tides forced at the boundary 
layer (Li and Smith 2010), but with lower frequencies that reflect its ultimately non-linear origin.

\section{Oceanic SST signal}

The fortnightly SST signal in this region was reported earlier by us (Ray and Susanto 2016). Figure 1a shows MSf amplitudes (in millikelvin) across the Indonesian seas, which were estimated by fitting 14.77-day sinusoids to a 13-year (2002-2014) time series of daily satellite-derived SST (simultaneous estimates of the seasonal cycle and a few other tidal frequencies were also included). We used the daily SST fields produced by Chin et al. $(2013,2017)$ for that analysis. Those SST data are based on both infrared and microwave measurements collected by a large number of satellites; the Chin et al. data have a relatively high spatial resolution as well as a relatively long time series length, both of which appear necessary to adequately extract the small, localized MSf signals. As Fig. 1a indicates, there is a diffuse noise background of about 30 $\mathrm{mK}$ across most of the region, and atop this background sit some large signals (in red) exceeding $100 \mathrm{mK}$, mostly confined to narrow straits and channels where tidal currents are known to be most intense (e.g., Hatayama et al. 1996; Ray et al. 2005; Ding et al. 2012). The interpretation is that these currents, which are especially intense during spring tides once a fortnight, lead to enhanced mixing which leads to a cooler SST with a relatively short delay of one to a few days (Ray and Susanto 2016).

Panels (b, c) of Fig. 1 zoom into the region of the Lesser Sunda Islands, showing a clearer view of the MSf amplitudes and also the phase lags. The amplitudes reach a maximum of approximately $160 \mathrm{mK}$ just south of Lombok Strait. This signal is smaller than the spring-neap differences observed by Iwasaki et al. (2015) in Japan, but the signal is robust and well above background noise levels, a fact evident from examination of an SST time series spectrum; see Fig. 3. Nugroho et al. (2018) have been able to reproduce a fortnightly SST signal very similar to that of Fig. 1b with a high-resolution 3-D numerical ocean circulation model.

To compute the phase lags of Fig. 1c, we needed to connect the SST measurement times to the times of peak spring-tide forcing, which occurs at times of full or new moon. A straightforward way to accomplish this is to follow standard tidal conventions by expressing the SST oscillations in form

$$
\mathrm{SST}=H \cos (\Theta(t)-G)
$$

for amplitude $H$ and phase lag $G$. For the MSf constituent, the argument $\Theta(t)=2 s(t)-2 h(t)$ where $s, h$ are the mean longitudes of the moon and sun, respectively, reckoned from the vernal equinox. The argument $\Theta(t)$ equals zero at times of lunar syzygy, i.e., at either new moon $(s=h)$ or full moon $\left(s=h+180^{\circ}\right)$. The mean longitudes can be evaluated from linear expressions in time (Pugh and Woodworth 2014; Egbert and Ray 2017):

$$
\begin{aligned}
& s=218.32+481267.88 T \\
& h=280.47+36000.77 T
\end{aligned}
$$

in degrees, where $T$ is time in Julian centuries $(36,525$ days) since noon, January 1,2000 . Note that in most ocean-tide calculations, Eq. (1) is augmented with additional amplitude and phase modulations, usually denoted $f(t), u(t)$, which account for the 18.6-y precession of the lunar orbit plane (Pugh and Woodworth 2014). In principle, we should do similarly by employing the standard modulations for $\mathrm{M}_{2}$ (not the linear MSf), but since the amplitude modulation of $\mathrm{M}_{2}$ is only $4 \%$, we ignore that small complication here.

\section{Meteorological response at Bali}

Variability of oceanic SST, including mesoscale variability (eddies, fronts, etc.), are known sources of variability in the overlying atmosphere (Small et al. 2008). Reported examples include responses in wind speed (e.g., Hayes et al. 1989; Chelton et al. 2001), air temperature, and atmospheric pressure (e.g., Lindzen and Nigam 1987). These air-sea interactions span typical periods of mesoscale variability from weekly to monthly (e.g., Hayes et al. 1989). To our knowledge, there are fewer reported cases at the small spatial scales, the high frequencies (fortnightly), and the small amplitudes (100 mK) of Fig. 1. But as Iwasaki et al. (2015) has previously discovered for the region surrounding the Seto Inland Sea, we have found an atmospheric response to SST fortnightly oscillations in the meteorological data at Bali, the island west of Lombok Strait.

The Bali meteorological data used here were collected at Ngurah Rai Airport, $8.75^{\circ} \mathrm{S}, 115.17^{\circ} \mathrm{E}$, and are in the form of daily means covering the period June 1973 through August 2016. There are a few single-point (1-day) gaps in the time series, which we have filled by linear interpolation. There are isolated outliers in some variables, which we have detected by a threshold analysis of fourth-differences; these isolated outliers have been replaced by linear interpolation across their neighboring points.

Calculation of time series spectra provides perhaps the most convincing evidence for a true fortnightlyand hence tidal-signal in the meteorological data. Such spectra are shown for Bali air temperature and relative humidity in Fig. 2. Small MSf tidal peaks can be seen sitting above the general background. The humidity peak is clear; the air temperature is somewhat less convincing, or at least less dominating over other general (non-tidal) variability, which is of course strong in this 14-day band 

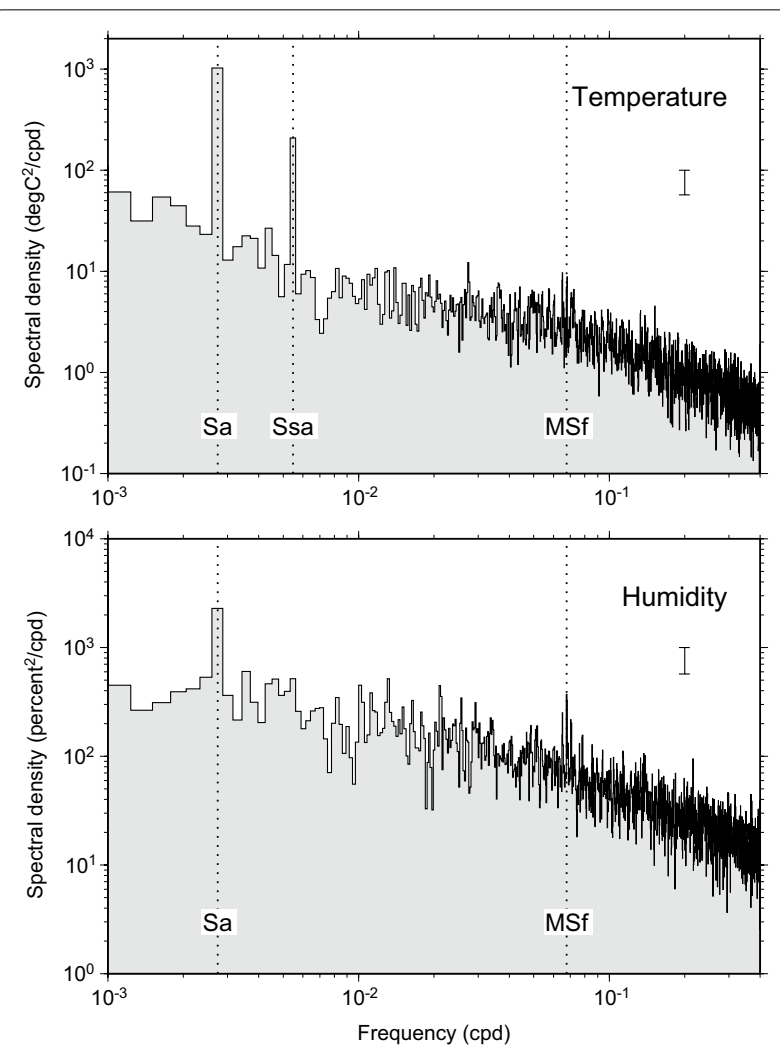

Fig. 2 Spectra of air temperature and relative humidity at Bali. Labels denote frequencies as follows: Sa (annual), Ssa (semiannual), MSf (14.77-day spring-neap cycle). Error bars, following Percival and Walden (1993, p. 300), give the $95 \%$ confidence interval for any peak relative to the background noise level

owing to typical frequencies of synoptic weather systems. The statistical significance of the peaks can be assessed by comparing the $95 \%$ confidence interval, following Percival and Walden (1993) and drawn as an error bar in the figure, with the height of each peak above its surrounding background level. The humidity peak is thus more robust than the temperature peak.

Zoom views of the spectra in the near-fortnightly band are shown in Fig. 3, along with a similar spectrum of SST for a point south of Lombok Strait, at $9^{\circ} \mathrm{S}, 115.5^{\circ} \mathrm{E}$, which is a location near the peak amplitudes shown in Fig. 1b. Interestingly, all three spectra of Fig. 3 show seasonal sidelines at frequencies \pm 1 cpy away from the central MSf frequency. This is not surprising in light of known seasonal dependencies in ocean stratification as well as monsoonal wind patterns in the region. In fact, in air temperature, one of the sidelines is slightly larger than the central line, and the other sideline is not so much a line but rather a broader 'hump' of energy smeared out across a band of frequencies, indicating additional intraannual modulations (which we ignore). The central humidity peak has a small shoulder, indicating some interannual variability, again not surprising. We have also examined other data collected at Bali, including air pressure and wind speed. Wind speed does have small peaks at the expected frequencies, but they are not especially convincing because of other nearby peaks and high background noise. For the other meteorological spectra, we have found no other tidal signals above background.

From each of the time series used to compute the spectra of Fig. 3, we have estimated mean tidal coefficients by least squares for the three frequencies in the fortnightly

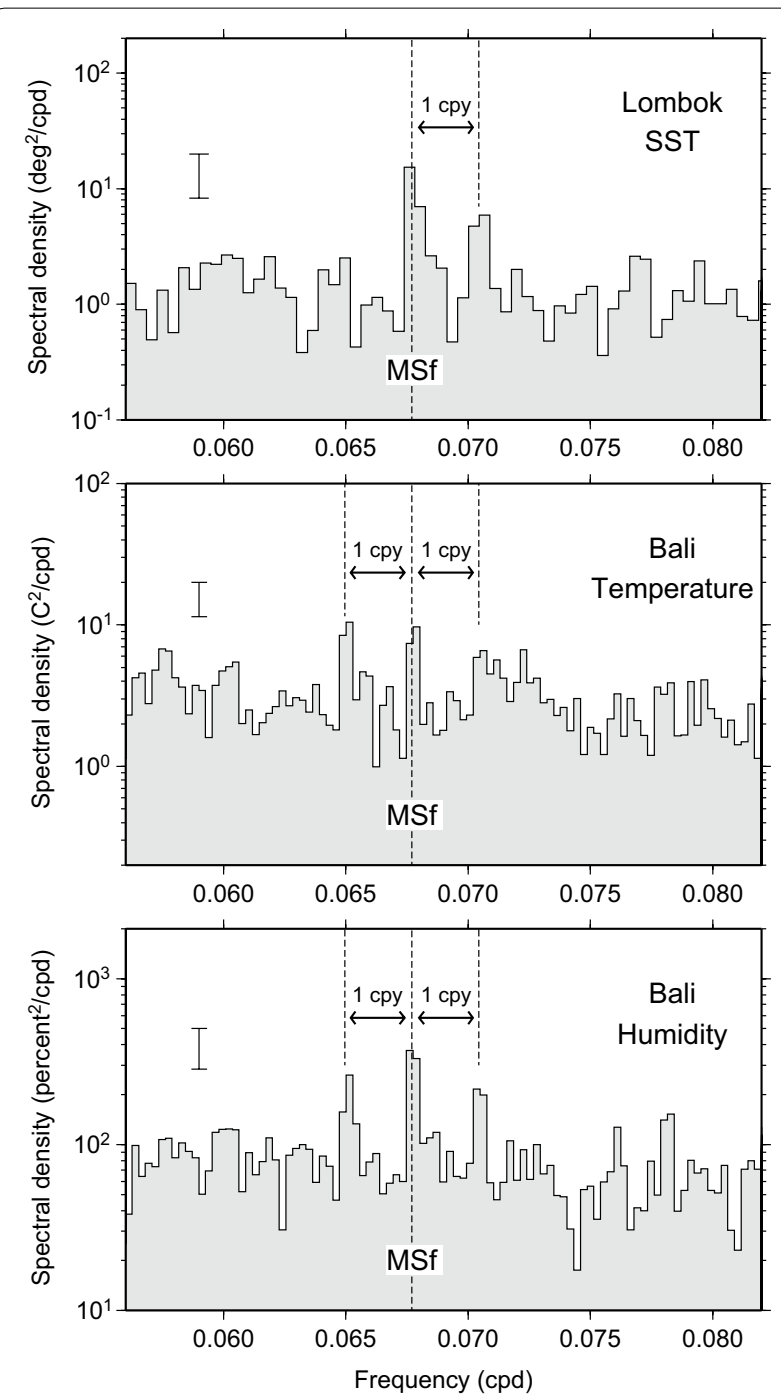

Fig. 3 Zoom views near the fortnightly tidal band for spectra of (top) SST at a location south of Lombok Strait near the MSf maximum, (middle) air temperature at the Bali meteorological station, (bottom) relative humidity at Bali. A central MSf peak is apparent in all three spectra, as are 1-cpy sidelines. The SST spectrum, being based on a shorter time series, has coarser frequency resolution than the Bali meteorological data. Error bars give $95 \%$ confidence interval for any peak relative to background noise level 
band: MSf and the two 1-cpy sidelines. No standard nomenclature exists for the two sidelines, so we here refer to them as MSfa and MSfb. Results are given in Table 1. In the table, the 'argument' column refers to $\Theta(t)$. Tabulated standard errors $(1 \sigma)$ are based on energy levels of the residual spectra in a neighborhood surrounding the estimated tides. In agreement with the spectral diagrams, the MSfa air temperature amplitude is slightly larger than the MSf amplitude. The MSfa SST amplitude does not exceed the $2 \sigma$ significance level, but all other amplitudes in the table do.

The estimates for tidal SST in Table 1 are for only a single location. The atmosphere, of course, will respond to potentially a wide area. We have therefore recomputed the SST values over a region in and around Lombok Strait, taking all locations with amplitudes exceeding $100 \mathrm{mK}$. The mean phase for these locations turns out to be $320^{\circ}$, which is close to the value listed in Table 1 . The standard deviation is $7^{\circ}$.

From the phases of the harmonics shown in Table 1, we can work out the relative phases of oceanic forcings and atmospheric responses. It is useful to begin, however, with the two semidiurnal constituents which form the ultimate spring-neap forcing of the SST oscillations.

The tide in this area is most accurately known at Benoa Harbor, near the southern tip of Bali, where a permanent tide gauge sits. The harbor has an entrance into Lombok Strait. From hourly data collected at Benoa during 20062017, we estimated a suite of tidal harmonic constants; values for some major constituents are listed in Table 2. Although the diurnal constituents are moderately large, the spring-neap cycle here is defined by the two dominant constituents in the semidiurnal band, $\mathrm{M}_{2}$ and $\mathrm{S}_{2}$. Their phases differ by $55^{\circ}$, which implies (Pugh and Woodworth 2014) an "age" of the tide at this port of 54 $\mathrm{h}$. This is the amount by which the observed peak spring tides lag the maximum spring-tide forcing. The value is in good agreement with that computed from a numerical tide model of the region (Ray and Susanto 2016, Fig. 4).

It is, of course, tidal currents that are responsible for mixing and the subsequent changes in SST. We therefore examined tidal current velocities from the FES2014 global barotropic model, an update to that described by
Lyard et al. (2006). Within the narrowest part of Lombok Strait, the model gives a spring-neap cycle in $\left(\mathrm{M}_{2}\right.$ plus $\mathrm{S}_{2}$ ) velocity magnitudes that peak roughly $65 \mathrm{~h}$ after lunar syzygy, or roughly the same "age" as obtained from the Benoa elevation time series. These model current speeds are drawn in Fig. 4 (lower panel) for a generic springneap cycle, and the 65-h (or 2.7 day) delay between time of lunar syzygy and time of peak currents is clear.

Also shown in Fig. 4 are the phases for the ocean SST and the Bali temperature and humidity. Since ocean mixing lowers the ocean surface temperature, the figure shows the phase of minimum SST and Bali air temperature (the phases of Table 1 correspond to temperature maxima). On average there is a suggestion of a small lag between the ocean and atmospheric variables and the maximum tidal currents. A lag is not unexpected for SST; a precise estimate of it can potentially give useful insight into ocean diffusivity properties (e.g., Garrett 1979). A lag between minimum SST and minimum air temperature, however, is not expected, and although uncertainties are large, Fig. 4 on its face suggests that Bali humidity leads SST, which must be rejected on physical grounds. It is possible that phase uncertainties have been underestimated. Alternatively, it is possible that the Bali meteorology is responding to SST over a smaller region than the large red patch shown in Fig. 1b. In particular, if Bali is responding to SST closer to the island coastline, then we should adopt an SST phase of around $80^{\circ}$ (corresponding to a temperature maximum of around $260^{\circ}$, as shown in Fig. 1c). This would place the SST phase consistently in line with the Bali meteorological phases. The question requires further investigation, and we can suggest at least two approaches to explore: (1) examine MSf phases from other meteorological stations in the region and determine if they are all regionally consistent or if they appear susceptible to local SST anomalies; (2) conduct experiments with a numerical atmospheric model forced by a varying SST, similar to that conducted by Iwasaki et al. (2015) for the Seto Inland Sea region. Each approach would be a useful exercise.

Regardless of the SST forcing, the Bali meteorological data at the fortnightly period of Table 1 and Fig. 4 show that air temperature and relative humidity are

Table 1 Amplitudes $\boldsymbol{H}$ and phase lags $\boldsymbol{G}$ of tidal components

\begin{tabular}{|c|c|c|c|c|c|c|c|c|}
\hline \multirow[t]{2}{*}{ Tide } & \multirow[t]{2}{*}{ Argument } & \multirow[t]{2}{*}{ Frequency $\left({ }^{\circ} / \mathrm{h}\right)$} & \multicolumn{2}{|c|}{ SST at $\left(9^{\circ} \mathrm{S}, 115.5^{\circ} \mathrm{E}\right)$} & \multicolumn{2}{|c|}{ Bali air temp. } & \multicolumn{2}{|c|}{ Bali rel. humidity } \\
\hline & & & $H$ & $G$ & $H$ & $G$ & $\bar{H}$ & $G$ \\
\hline MSfa & $2 s-3 h$ & 0.97483 & $49 \pm 25$ & $183 \pm 30$ & $80 \pm 19$ & $171 \pm 14$ & $0.36 \pm 0.10$ & $351 \pm 17$ \\
\hline MSf & $2 s-2 h$ & 1.01590 & $143 \pm 25$ & $322 \pm 10$ & $66 \pm 19$ & $290 \pm 16$ & $0.49 \pm 0.10$ & $99 \pm 12$ \\
\hline MSfb & $2 s-h$ & 1.05696 & $80 \pm 25$ & $90 \pm 18$ & $62 \pm 19$ & $54 \pm 18$ & $0.42 \pm 0.10$ & $231 \pm 14$ \\
\hline
\end{tabular}

Amplitude units: $\mathrm{mK}$ for temperatures, percent for relative humidity. Phase lag units: degrees 


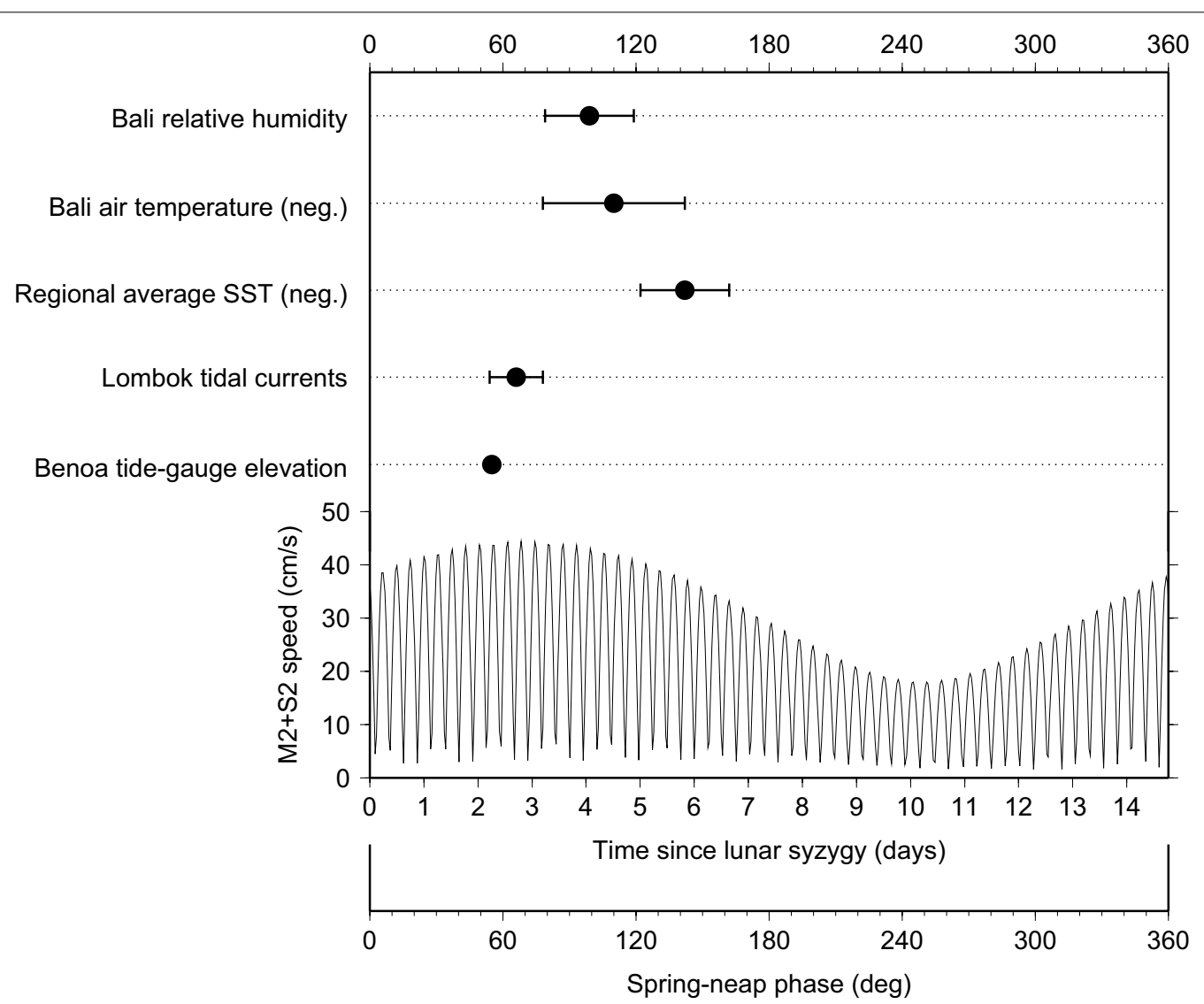

Fig. 4 MSf phase lags, i.e., times within a spring-neap cycle of (top to bottom): maximum relative humidity at Bali; minimum air temperature at Bali; minimum SST in a region surrounding Lombok Strait; maximum tidal current speeds within Lombok Strait; and maximum spring-tide elevations at the Benoa tide gauge. Uncertainties represent $\pm 2 \sigma$. The tidal semidiurnal currents are extracted from the barotropic finite-element model FES2014 (updated Lyard et al. 2006), which are drawn out explicitly in the lower panel

Table 2 Amplitudes and Greenwich phase lags of major ocean tides at Benoa Harbor

\begin{tabular}{lcc}
\hline Tide & Amplitude $(\mathbf{m m})$ & Phase \\
\hline Sa & 150 & $330^{\circ}$ \\
Ssa & 61 & $167^{\circ}$ \\
$\mathrm{O}_{1}$ & 162 & $156^{\circ}$ \\
$\mathrm{P}_{1}$ & 73 & $173^{\circ}$ \\
$\mathrm{K}_{1}$ & 253 & $177^{\circ}$ \\
$\mathrm{N}_{2}$ & 114 & $28^{\circ}$ \\
$\mathrm{M}_{2}$ & 642 & $53^{\circ}$ \\
$\mathrm{S}_{2}$ & 367 & $108^{\circ}$ \\
$\mathrm{K}_{2}$ & 102 & $106^{\circ}$ \\
\hline
\end{tabular}

anti-correlated. The phase differences show air temperature and humidity for all three harmonics of Table 1 are almost perfectly out of phase: $180^{\circ} \pm 22^{\circ}$, $191^{\circ} \pm 20^{\circ}, 177^{\circ} \pm 23^{\circ}$. In a study of synoptic-scale covariations of surface air temperature and relative humidity over the global ocean, Pfahl and Niedermann (2011) found that the two variables are negatively correlated in tropical latitudes and positively correlated in mid-latitudes. Our results for tidal oscillations at the fortnightly period are thus consistent with their synoptic data. Pfahl and Niedermann argue the negative correlation in the tropics is related to convective precipitation, as precipitation is associated with decreases in temperature but increases in relative humidity. In our case, we found no evidence of enhanced fortnightly energy in Bali precipitation.

\section{Seasonality}

As the spectra presented above make clear, there are strong seasonal dependencies on all variables of interest. This section examines in more detail the seasonality of the three primary variables of Table 1 . 
For any of the listed variables of Table 1, the time dependence can be written out explicitly in terms of the three tabulated constituents as

$$
\begin{aligned}
y(t)= & H_{a} \cos \left(\omega_{a} t-G_{a}\right)+H \cos (\omega t-G) \\
& +H_{b} \cos \left(\omega_{b} t-G_{b}\right),
\end{aligned}
$$

where subscripts $a$ refer to the MSfa harmonic and $b$ to the MSfb harmonic, and where

$$
\omega_{a}=\omega-\Delta \omega, \quad \omega_{b}=\omega+\Delta \omega
$$

with $\Delta \omega=1$ cpy. Connection to the moon's phases is made by setting $\omega t=\Theta(t)$. By employing simple trigonometric addition formulas, $y(t)$ can be rewritten in terms of a single sinusoid with seasonally varying amplitude and phase:

$$
\begin{aligned}
& y(t)=\widetilde{H}(t) \cos (\Theta(t)-\widetilde{G}) \\
& =\widetilde{X}(t) \cos \Theta(t)+\widetilde{Y}(t) \sin \Theta(t),
\end{aligned}
$$

where

$$
\begin{aligned}
\widetilde{X}= & H \cos G \\
& +H_{a} \cos \Delta \omega t \cos G_{a}-H_{a} \sin \Delta \omega t \sin G_{a} \\
& +H_{b} \cos \Delta \omega t \cos G_{b}+H_{b} \sin \Delta \omega t \sin G_{b}
\end{aligned}
$$

$$
\begin{aligned}
\widetilde{Y}= & H \sin G \\
& +H_{a} \sin \Delta \omega t \cos G_{a}+H_{a} \cos \Delta \omega t \sin G_{a} . \\
& -H_{b} \sin \Delta \omega t \cos G_{b}+H_{b} \cos \Delta \omega t \sin G_{b}
\end{aligned}
$$

The seasonal variations of the three variables of Table 1 are shown explicitly in Fig. 5. In each panel, the dotted line delineates the seasonal envelope as defined by the amplitude $\widetilde{H}$. The fortnightly oscillations themselves are evaluated directly from (4). (The phases of the fortnightly variations within the seasonal envelopes depend on $\Theta(t)-$ i.e., on the phases of the moon-and the figure as drawn uses actual phases for year 2010.)

All variables in Fig. 5 are seen to peak during the boreal summer. Boreal summer is the season of the southeast monsoon, with pronounced effects on the regional oceanography and climate (e.g., Gordon 2005). The southeasterly winds are accompanied by upwelling and cooler SST, and the Lombok Strait transport, one of the main channels of the Indonesian Throughflow, strengthens, amounting to approximately one-quarter of the entire throughflow in contrast to other seasons when it amounts to far less and is more variable (Sprintall et al. 2009). Tidal mixing, and hence the fortnightly SST oscillations, depends on the generation and dissipation of tidal internal waves, and work by Matthews et al. (2011) explores how these vary with season. Based on analysis of radar imagery, they find that the southeast monsoon season is characterized by relatively large numbers of irregular (as opposed to arc-like) packets of solitons propagating southwards out of Lombok Strait. In other seasons, more regular arc-like packets are seen traveling both northwards and southwards from the strait.

Once fortnightly SST signals are set up, which as Fig. 1 shows are most apparent off the southeast coast of Bali, the southeast monsoonal winds are in exactly the right direction to affect Bali meteorological measurements. We therefore must expect strongest atmospheric response during this season, no matter the physical mechanisms at work within the ocean interior.

Figure 5, however, also shows slightly strengthened MSf atmospheric signals during boreal winter, although it is not clear how significant these are. The signal is clearer in air temperature. We estimate the winter temperature standard errors are roughly $30 \mathrm{mK}$, which is nearly half the observed wintertime amplitudes. Recall too that the air temperature spectrum (Fig. 3) showed the least convincing MSf peaks relative to background. If real, however, an explanation is needed for the insignificant wintertime SST amplitudes in Fig. 5. At least two possibilities suggest themselves: (1) The SST time series of Fig. 5 is based on the harmonic constants at only one location $\left(9^{\circ} \mathrm{S}, 115.5^{\circ} \mathrm{E}\right)$, and there may be other locations in the surrounding ocean where a wintertime signal is larger. (2) It is possible that the satellite SST data we employ-notably the infrared measurements that provide the high spatial resolutions needed for this workhave been systematically corrupted by cloud cover, which is prevalent during the boreal winter. We are currently investigating other satellite SST products, including some which do not interpolate across times of data gaps.

\section{Conclusions}

Ocean tidal mixing in the Indonesian seas is a known important mechanism for modifying water properties of the Indonesian Throughflow (Koch-Larrouy et al. 2010; Sprintall et al. 2014). The mixing appears mostly localized to a number of narrow straits and channels, including Lombok Strait. Within and around Lombok Strait, mixing has been shown to generate a clear fortnightly signal in the sea surface temperature (Ray and Susanto 2016). As shown here, these oceanic SST signals can generate a small, but detectable, signature in meteorological observations on Bali, a peculiar kind of atmospheric tide with fortnightly periodicity. The signals are most apparent during boreal summer.

Jochum and Potemra (2008), using a coupled climate model, have previously shown how enhanced ocean mixing in the Indonesian seas modifies tropical precipitation and convection patterns in the region. The air-sea 

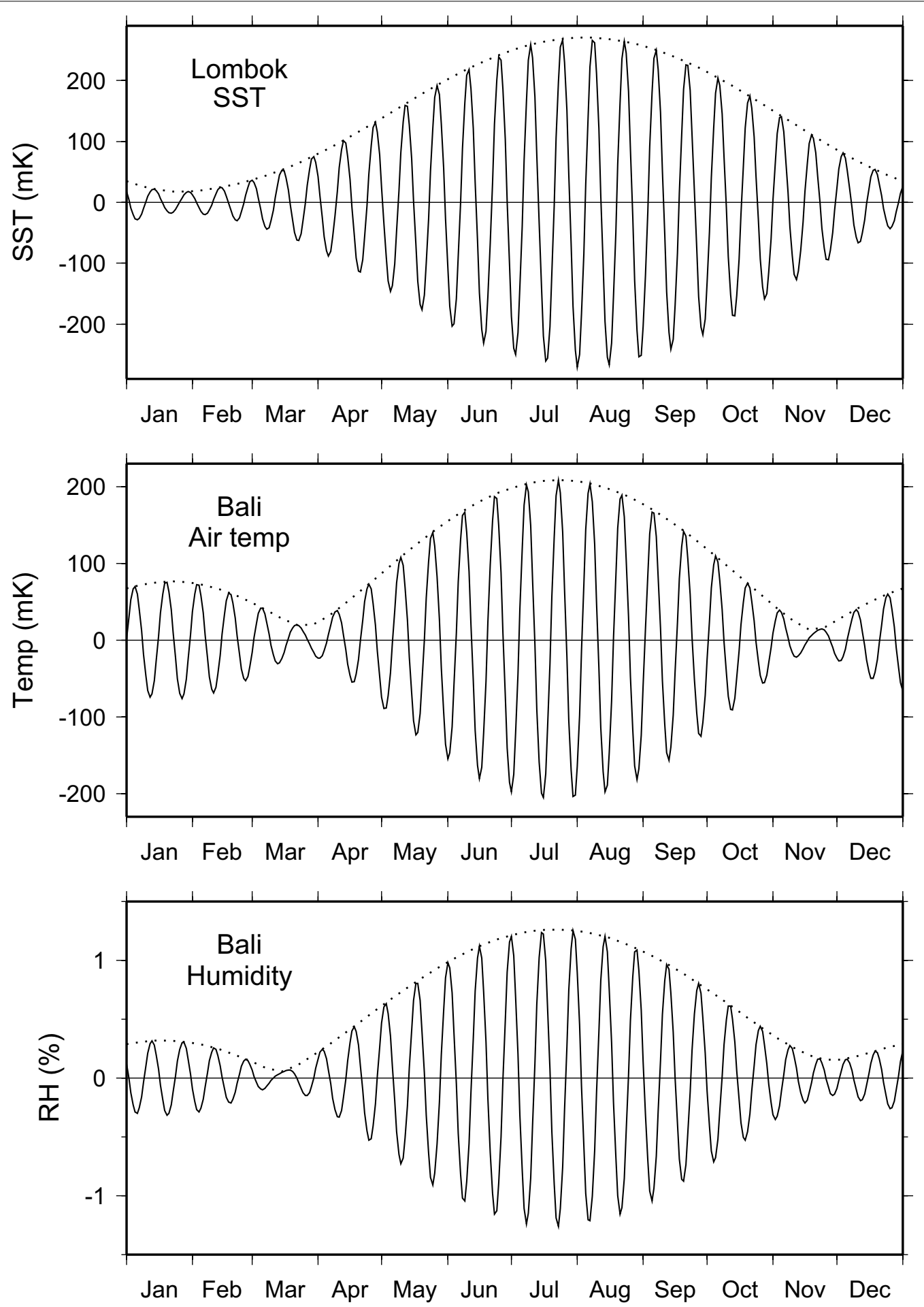

Fig. 5 Seasonal variations of the fortnightly oscillations in SST south of Lombok Strait and in Bali air temperature and Bali relative humidity. The dotted lines delineate the seasonal envelope of the fortnightly signals; these envelopes are evaluated from $\widetilde{H}, \widetilde{G}$ of Eq. (5), with constants from Table 1. The fortnightly signals all peak during boreal summer 
interaction reported here is on a much faster time scale, at the fortnightly (14.77 day) period of the lunisolar spring-neap cycle. The signals detected in SST and in surface air temperature and humidity are very small, as shown in Fig. 5; they are easily overlooked and can surely be neglected in most discussions of Indonesia's climate. Nonetheless, even very small tidal signals can act as useful probes because of their recognizable frequency signatures. Follow-up study may better reveal the connections between regional tidal currents and local meteorology, including why the MSf humidity signals are so much more pronounced than the temperature signals (Fig. 3), why they are $180^{\circ}$ out of phase (cf. Pfahl and Niedermann 2011), and how the signals change over time.

\section{Authors' contributions}

RDS discovered the fortnightly atmospheric response at Bali. RDR performed the tidal analyses and wrote most of the paper. Both authors contributed to the discussion. Both authors read and approved the final manuscript.

\section{Author details}

${ }^{1}$ Geodesy \& Geophysics Lab, NASA Goddard Space Flight Center, Greenbelt 20771, USA. ${ }^{2}$ Dept. Atmospheric \& Oceanic Science, University of Maryland, College Park, MD, USA. ${ }^{3}$ Faculty of Earth Science and Technology, Bandung Institute of Technology, Bandung, Indonesia.

\section{Acknowledgements}

The Bali meteorological data were obtained courtesy of Dr. Andri Ramdhani from the Agency for Meteorology, Climatology, and Geophysics, Indonesia. Bali temperature data are included in the Global Historical Climatology Network database from the NOAA National Climatic Data Center.

\section{Competing interests}

The authors declare that they have no competing interests.

\section{Availability of data and materials}

Please contact authors for data requests.

\section{Funding}

The study was funded by the Physical Oceanography program of the U.S. National Aeronautics and Space Administration, including through Grant \# 80NSSC18K0777 and Jet Propulsion Laboratory subcontract \# 1554354 to the University of Maryland.

\section{Publisher's Note}

Springer Nature remains neutral with regard to jurisdictional claims in published maps and institutional affiliations.

Received: 30 January 2019 Accepted: 16 April 2019

Published online: 30 April 2019

\section{References}

Bisagni JJ, Sano MH (1993) Satellite observations of sea surface temperature variability on southern Georges Bank. Cont Shelf Res 13:1045-1064

Chelton DB, Esbensen SK, Schlax MG, Thum N, Freilich MH (2001) Observations of coupling between surface wind stress and sea surface temperature in the eastern tropical Pacific. J Clim 14:1479-1498

Chin TM, Vazquez J, Armstrong E (2013) Algorithm theoretical basis document: a multi-scale, high-resolution analysis of global sea surface temperature, vers. 1.3. Jet Propulsion Laboratory, Pasadena
Chin TM, Vazquez-Cuervo J, Armstrong EM (2017) A multi-scale high-resolution analysis of global sea surface temperature. Remote Sens Environ 200:154-169

Ding Y, Bao X, Yu H, Kuang L (2012) A numerical study of the barotropic tides and tidal energy distribution in the Indonesian seas with the assimilated finite volume coastal ocean model. Ocean Dyn 62:515-532

Egbert GD, Ray RD (2017) Tidal prediction, in: the sea: science of ocean prediction. J Mar Res 75:189-237

Garrett C (1979) Mixing in the ocean interior. Dyn Atmos Oceans 3:239-265

Gordon AL (2005) Oceanography of the Indonesian seas and their throughflow. Oceanography 18(4):14-27

Griffin DA, LeBlond PH (1990) Estuary/ocean exchange controlled by springneap tidal mixing. Estuar Coastal Shelf Sci 30:275-297

Hatayama T, Awaji T, Akitomo K (1996) Tidal currents in the Indonesian seas and their effect on transport and mixing. J Geophys Res 101:12,353-12,373

Hayes SP, McPhaden MJ, Wallace JM (1989) The influence of sea-surface temperature on surface wind in the eastern equatorial Pacific: weekly to monthly variability. J Clim 2:1500-1506

Iwasaki S, Isobe A, Miyao Y (2015) Fortnightly atmospheric tides forced by spring and neap tides in coastal waters. Sci Rep 5(10):167. https://doi. org/10.1038/srep 10167

Jochum M, Potemra J (2008) Sensitivity of tropical rainfall to the Banda Sea diffusivity in the community climate system model. J Clim 21:6445-6454

Koch-Larrouy A, Lengaigne M, Terray P, Madec G, Masson S (2010) Tidal mixing in the Indonesian Seas and its effect on the tropical climate system. Clim Dyn 34:891-904. https://doi.org/10.1007/s00382-009-0642-4

Li Y, Smith RB (2010) Observation and theory of the diurnal continental thermal tide. J Atmos Sci 67:2752-2765

Lindzen RS, Nigam S (1987) On the role of sea surface temperature gradients in forcing low-level winds and convergence in the tropics. J Atmos Sci 44:2418-2436

Lyard F, Lefevre F, Letellier T, Francis O (2006) Modelling the global ocean tides: modern insights from FES2004. Ocean Dyn 56:394-415

Matthews JP, Aiki H, Masuda S, Awaji T, Ishikawa Y (2011) Monsoon regulation of Lombok Strait internal waves. J Geophys Res 116(C05):007. https://doi. org/10.1029/2010JC006403

Nugroho D, Koch-Larrouy A, Gaspar P, Lyard F, Reffray G, Tranchant B (2018) Modelling explicit tides in the Indonesian seas: an important process for surface sea water properties. Mar Pollut Bull 131B:7-18

Paden CA, Abbott MR, Winant CD (1991) Tidal and atmospheric forcing of the upper ocean in the Gulf of California: 1. Sea surface temperature variability. J Geophys Res 96:18,337-18,359

Percival DB, Walden AT (1993) Spectral analysis for physical applications. Cambridge Univ. Press, Cambridge

Pfahl S, Niedermann N (2011) Daily covariations in near-surface relative humidity and temperature over the oceans. J Geophys Res 116(D19):104

Pugh DT, Woodworth PL (2014) Sea level science: understanding tides, surges, tsunamis and mean sea-level changes. Cambridge Univ. Press, Cambridge

Ray RD, Susanto RD (2016) Tidal mixing signatures in the Indonesian seas from high-resolution sea surface temperature data. Geophys Res Lett 43:8115-8123. https://doi.org/10.1002/2016GL069485

Ray RD, Egbert GD, Erofeeva SY (2005) A brief overview of tides in the Indonesian Seas. Oceanography 18:74-79

Small SJ, deSzoeke SP, Xie SP, O'Neill L, Seo H, Song Q, Cornillon P, Spall M, Minobe S (2008) Air-sea interaction over ocean fronts and eddies. Dyn Atmos Oceans 45:274-319

Souza AJ, Pineda J (2001) Tidal mixing modulation of sea-surface temperature and diatom abundance in Southern California. Cont Shelf Res 21:651-666

Sprintall J, Wijffels S, Molcard R, Jaya I (2009) Direct estimates of the Indonesian throughflow entering the Indian Ocean: 2004-2006. J Geophys Res 114(C07):001. https://doi.org/10.1029/2008JC005257

Sprintall J, Gordon AL, Koch-Larrouy A, Lee T, Potemra JT, Pujiana K, Wijffels S (2014) The Indonesian Seas and their role in the coupled ocean-climate system. Nature Geosci 7:487-492 